\title{
Isparta Koşullarında Düzlemsel Su Isıtmalı Güneş Kollektörlerinde Farklı Tasarım Özelliklerinin Enerji ve Verim Üzerine Etkilerinin Belirlenmesi
}

\author{
Recep Külcü ${ }^{1 *}$ \\ ${ }^{1}$ Isparta Uygulamalı Bilimler Üniversitesi Ziraat Fakültesi Tarım Makineleri ve Teknolojileri Mühendisliği Bölümü, Isparta. (ORCID: 0000-0002-7185-6514)
}

(İlk Geliş Tarihi 24 Eylül 2020 ve Kabul Tarihi 14 Aralık 2020)

(DOI: 10.31590/ejosat.799663)

ATIF/REFERENCE: Külcü, R. (2020). Isparta Koşullarında Düzlemsel Su Isıtmalı Güneş Kollektörlerinde Farklı Tasarım ve Malzeme Kullanımının Enerji ve Verim Üzerine Etkilerinin Belirlenmesi. Avrupa Bilim ve Teknoloji Dergisi, (20), 949-956.

\section{$\ddot{\mathbf{O z}}$}

Dünya'da küresel ısınmaya neden olan sera gazı emisyonlarının temel kaynağı fosil enerji kaynaklarının yoğun olarak kullanılmasıdır. Fosil enerji kaynaklarının alternatifi yenilenebilir enerji kaynaklarıdır. Güneş enerjisi, yenilenebilir ve yakıt kullanmayan özelliğiyle en temiz enerji kaynağı olarak kabul edilmektedir. Güneş enerjisi; elektrik ve 1sıl dönüşümler yoluyla kullanılmaktadır. Güneş enerjisinden 1sıl enerji dönüşümünde güneş kollektörleri kullanılmaktadır.

Güneş kollektörleri hava ve su 1sıtma amacıyla tasarlanmış sistemlerdir. Bu çalışmada; Isparta koşullarında güneş kollektörlerinde, farklı tasarım ve malzeme kullanımının üretilecek enerji ve kollektör verimi üzerine etkilerinin belirlenmesi hedeflenmiştir. Kollektörlerde malzeme olarak farklı yutucu yüzey ve izolasyon maddeleri öngörülmüştür. Hesaplamalarda, 7 yutucu yüzey ve 5 yalıtım malzemesi kullanımına göre kurgular yapılmıştır. Tasarım parametresi olarak yalıtım malzemesi kalınlığı ve boru sayısı kullanılmıştır. Çalışmada 4 farklı boru sayısı ve 4 farklı yalıtım malzemesi kalınlığı için simülasyonlar gerçekleştirilmiştir. Çalışma sonucunda; Isparta koşulları için en uygun eğim açısının $28^{\circ}$ olduğu tespit edilmiştir. Yalıtım ve yüzey malzemesi kullanımıyla kollektörlerin yıllık veriminin \%30'dan \%44'e yükselebileceği ve tasarım parametreleriyle bu verimin \%47 seviyelerine taşınabileceği ortaya konulmuştur.

Anahtar Kelimeler: Isparta, Güneş enerjisi, Güneş kollektörü, Yutucu yüzey, Yalıtım malzemesi

\section{Determination of the Effects of Using Different Designs on Energy and Efficiency in Flat Plate Water Heated Solar Collectors in Isparta Conditions}

\begin{abstract}
The main source of greenhouse gas emissions that cause global warming in the world is the intense use of fossil energy resources. Alternative to fossil energy sources are renewable energy sources. Solar energy is regarded as the cleanest energy source as a renewable and fuel-free resource. Solar energy; it is used through electrical and thermal transformations. Solar collectors are used in thermal energy conversion from solar energy.

Solar collectors are used for air and water heating. In this study, it is aimed to determine the effects of using different designs and materials on solar collectors used in Isparta conditions on the energy and collector efficiency to be produced. Different absorbing surface and isolation materials have been foreseen as materials in the collectors. In the calculations, the use of 7 absorptive surfaces and 5 insulation materials has been predicted. Insulation material thickness and pipe number are used as design parameters. In the study, simulations were carried out for 4 different pipe numbers and insulation material thickness. In the results of study; it was determined that the most suitable angle of inclination for Isparta conditions was $28^{\circ}$. It has been demonstrated that the annual efficiency of collectors can increase from $30 \%$ to $44 \%$ with the use of insulation and surface material, and this efficiency can be increased to $47 \%$ with design parameters.
\end{abstract}

Keywords: Isparta, Solar energy, Solar collectors, Absorber, Isolation materials

\footnotetext{
* Sorumlu Yazar Isparta Uygulamalı Bilimler Üniversitesi Ziraat Fakültesi Tarım Makineleri ve Teknolojileri Mühendisliği Bölümü, Türkiye, ORCID0000-0002-7185-6514, recepkulcu@isparta.edu.tr
} 


\section{Giriş}

Dünyamız son yüzyılda sera gazı emisyonların sonucunda küresel 1sınma ve bu 1sınma nedeniyle ortaya çıkan iklim değişiklikleriyle karşı karşıya kalmıştır. Dünya üzerinde yaşamın ve faaliyetlerin sürdürülebilirliği için sera gazı emisyonlarının azaltılması büyük önem taşımaktadır. Sera gazı emisyonlarının temel nedeni fosil enerji kaynaklarının yoğun olarak kullanılmasıdır. $\mathrm{Bu}$ bağlamda fosil enerji kaynaklarından yenilenebilir enerji kaynaklarına geçiş kritik öneme sahiptir.

Yenilenebilir enerji kaynakları içerisinde güneş enerjisi, yakıt kullanmayan özelliğiyle en temiz kaynak olarak kabul edilmektedir. Güneş enerjisi elektrik ve 1sıl enerji üretiminde kullanılmaktadır. Elektrik üretiminde fotovoltaik sistemler kullanılırken, 1sıl dönüşümlerde kollektörler kullanılmaktadır. Kollektörler kullanım amacına bağlı olarak hava ve su 1sıtmalı olarak tasarlanmaktadırlar.

Su ısıtma amaciyla tasarlanan güneş kollektörleri, konutlarda, yüzme havuzlarında, otellerde ve bazı sanayi işletmelerinde sıcak su ihtiyacının karşılanması amacıyla kullanılmaktadır. $\mathrm{Bu}$ kollektörler yaygın olarak düzlem yüzeylidirler ancak son yıllarda vakum tüplü modellerin de yayınlaşmaya başladığı bilinmektedir. Dünyada 2014 yılı itibariyle güneş enerjisinden 1sıl enerji üretmek amacıyla kullanılan kollektör alanı 530 milyon $\mathrm{m}^{2}$ ve kurulu güç $406000 \mathrm{MW}$ seviyesine ulaşmıştır. Bu sistemlerden yılda 36,7 MTEP petrol tasarrufunda bulunulmuş ve bunun sonucunda 118,6 milyon ton $\mathrm{CO}_{2}$ emisyonu azaltılmıştır. Ülkemizde ise 16 milyon $\mathrm{m}^{2}$ kollektör alanıyla yılda 1 MTEP enerji tasarrufu gerçekleştirilmekte ve bunun sonucunda 1,6 milyon ton $\mathrm{CO}_{2}$ emisyonu azaltılmaktadır. Ayrıca ülkemiz yılda 1,6 milyon $\mathrm{m}^{2}$ kollektör üretim potansiyeli ile pazarda önemli bir aktör haline gelmiştir (GÜNDER, 2020).

$\mathrm{Su}$ 1sıtmalı güneş kollektörleri; güneşten gelen 1şınımların yutucu yüzey üzerinde 1sı enerjisine dönüştürülmesi ve bu ısının, yutucu yüzey içerisinde oluşturulan borulardan geçen suya aktarılması prensibine göre çalışmaktadır. Kollektörler bir kasa korumasına alınmakta, 1sı kayıplarını azaltmak amacıyla izolasyon malzemesi kullanılmakta ve üst yüzey kayıplarını azaltmak amacıyla genellikle cam üst örtü ile kapatılmaktadır (Şekil 1).

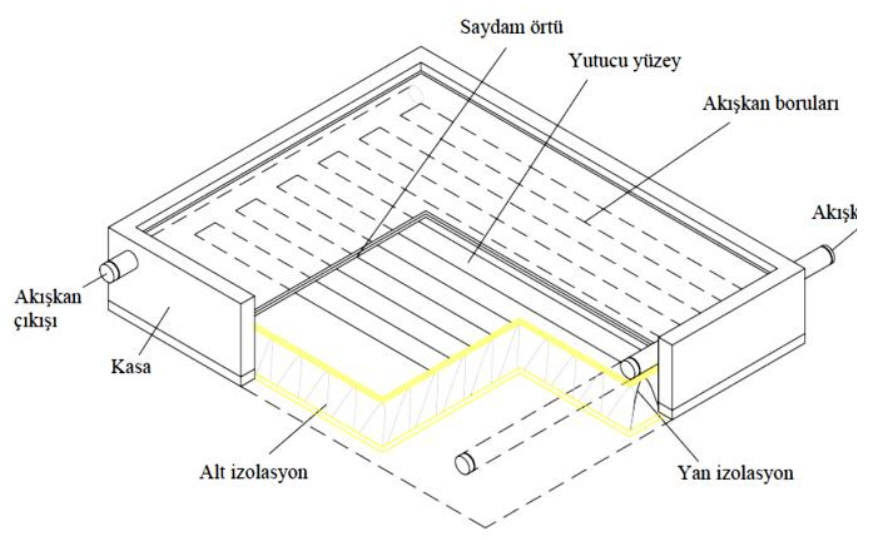

Şekil 1. Su 1sıtmalı güneş kollektörü (Tirıs, 1997)

Güneş kollektörlerinde kullanılan malzeme ve tasarım parametreleri elde edilecek verim ve ısıl enerji miktarını doğrudan etkilemektedir. Kullanılan izolasyon malzemesinin kalınlığ 1 ve ısı iletim katsayısı, kullanılan boru sayısı, yutucu yüzeyin yutma ve yayma oranları kollektör verimini etkilemektedir. Bu etki gelen e-ISSN: 2148-2683 ışınım miktarı ve açılarına bağlı olduğu için değişiklikler kollektörün bulunduğu lokasyona göre değişim göstermektedir.

Shariah vd. (2019) su 1sıtmalı güneş kolektörleri konsunda gerçekleştirdikleri kuramsal çalışmada, kollektör yutucu yüzey plakasının malzemesinin verim üzerine etkilerini incelemişlerdir. Çalışma sonuçlarına göre çelik sac yerine alüminyum plaka kullanımının verimi \%4-7 oranında arttırdığını tespit etmişlerdir. Alüminyum yerine bakır plaka kullanımı ise verimi \%3 (Çelik saca göre \%7-11) oranında arttırdığını bildirmişlerdir. Kılıçkap vd. (2015) Elazığ ilinde siyah mat boya kullanılan standart bir güneş kollektörünün verimini deneysel koşullarla belirlemişlerdir. Denemelerinde temmuz ayında anlık verim değerleri \%35-56 arasında değişirken, kasım ayında verim değerleri \%35-51 arasında değişim göstermiştir. Kumar ve Rosen (2010) çalımalarında güneş kollektörlerinde izolasyon kullanımının verime etkilerine değerlendirmişlerdir. İzolasyon kullanılması durumunda verimi \%46,8 olarak hesaplamışlar ve izolasyon kullanılmaması durumunda verimin $\% 40$ seviyesine düşeceğini belirlemişlerdir.

Çalışma kapsamında, güneş kollektörlerinde farklı yutucu yüzey ve yalıtım malzemesi ile farklı boru sayısı kullanımının verim üzerine etkilerinin belirlenmesi hedeflenmiştir. Kuramsal nitelikte yapılan çalışma kapsamında kollektörün Isparta koşullarında kullanımı öngörülerek hesaplamalar gerçekleştirilmiştir. Elde edilece sonuçların Isparta koşullarında hangi kollektör tasarımının ne ölçüde başarılı olacağı konusunda aydınlatıcı veriler ortaya çıkartması hedeflenmiştir.

\section{Materyal ve Metot}

Çalışma kapsamında; Isparta ilinde farklı yutucu yüzey ve izolasyon malzemesine ile farklı boru sayısı ve yalıtım kalınlığına sahip düzlem yüzeyli güneş kollektörlerinin su 1sıtma amacıyla kullanılması ile elde edilecek enerji miktarlarının hesaplanması ve yıl içerisindeki enerji değişiminin simülasyonunun yapılması hedeflenmiştir. Kuramsal olarak gerçekleştirilen çalışmada rüzgâr hızı ve sıcaklık gibi veriler T.C. Meteoroloji Genel Müdürlüğünden temin edilmiştir. Hesaplamalarda kollektöre ait bazı özellikler, kullanımda olan sistemlerin tasarım parametreleri dikkate alınarak Tablo 1'deki gibi kabul edilmiştir.

Tablo 1. Hesaplamalarda kullanılan kollektöre ait bazı özellikler

\begin{tabular}{|l|r|}
\hline Kollektör uzunluğu & $1,94 \mathrm{~m}$ \\
\hline Kollektör yüksekliği & $0,1 \mathrm{~m}$ \\
\hline Kollektör genişliği & $0,94 \mathrm{~m}$ \\
\hline Toplayıcı sac kalınlığı & $0,5 \mathrm{~mm}$ \\
\hline Boruların iç çap1 & $10 \mathrm{~mm}$ \\
\hline Suyun debisi & $0,02 \mathrm{~kg} / \mathrm{s} \mathrm{m}^{2}$ \\
\hline Camın yayma katsayısı & 0,08 \\
\hline Enlem açısı (Isparta) & 37,75 \\
\hline Cam üst örtü sayısı & 1 \\
\hline
\end{tabular}

Çalışma kapsamında güneş kollektörlerinde farklı yutucu yüzey ve yalıtım malzemesi kullanımının etkilerinin belirlenmesi hedeflenmektedir. $\mathrm{Bu}$ kapsamda, hesaplamalara dâhil edilen yutucu yüzey malzemesi ve özellikleri Tablo 2'de ve yalıtım malzemeleri ile özellikleri Tablo 3'de gösterilmiştir. Yutucu yüzey malzemeleri A-F harfleriyle simgelenmiştir. A dişındaki diğer yutucu yüzeyler seçici yüzey olarak adlandırılmaktadır. $\mathrm{Bu}$ yüzeylerin temel özelliği 1 sı 1şınlarını yayma oranlarının 
düşürülmüş olmasıdır. Seçici yüzey kaplamaları özel tasarlanmış ticari ürünlerdir. Tablo 2'de bu ürünlerin ticari isimleri ve üretici firmaları da gösterilmiştir. A kaplaması ise seçici değildir ve

Tablo 2. Kollektör yüzeylerinde kullanılan yutucu yüzey malzemeleri ve özellikleri birçok firma tarafından düşük maliyetli olması nedeniyle tercih edilmektedir.

(Korkmaz, 2006; Madhukeshwara ve Prakash, 2012, Sakall, 2005)

\begin{tabular}{|c|c|c|c|c|c|c|c|c|}
\hline Simge & $\begin{array}{l}\text { Kolektör } \\
\text { Yapımcı } \\
\text { Firma }\end{array}$ & $\begin{array}{l}\text { Yutucu } \\
\text { Kaplama } \\
\text { Yapımcı } \\
\text { Firma }\end{array}$ & $\begin{array}{c}\text { Yutucunun } \\
\text { Ticari } \\
\text { İsmi }\end{array}$ & $\begin{array}{l}\text { Yutucu } \\
\text { Kaplama } \\
\text { Türü }\end{array}$ & Malzeme & $\begin{array}{l}\text { Malzemenin } \\
\text { Isıl İletkenliği } \\
(\mathbf{W} / \mathbf{m ~ K})\end{array}$ & $\begin{array}{c}\text { Yutma } \\
\text { Katsayısı } \\
\left(\alpha_{n}\right)\end{array}$ & $\begin{array}{c}\text { Yayma } \\
\text { Katsayısı } \\
(\varepsilon p)\end{array}$ \\
\hline A & - & - & $\begin{array}{l}\text { Siyah Mat } \\
\text { Boya }\end{array}$ & $\begin{array}{l}\text { Boya } \\
\text { Malzemesi }\end{array}$ & $\begin{array}{c}\text { Galvanizli } \\
\text { sac }\end{array}$ & 16 & 0,94 & 0,88 \\
\hline B & $\begin{array}{l}\text { Agena SA, } \\
\text { İsviçre }\end{array}$ & $\begin{array}{l}\text { Energie } \\
\text { Solarie SA } \\
\text { İsviçre }\end{array}$ & $\begin{array}{l}\text { Energie } \\
\text { Solarie }\end{array}$ & $\begin{array}{l}\text { Siyah } \\
\text { krom }\end{array}$ & $\begin{array}{l}\text { Galvanizli } \\
\text { sac }\end{array}$ & 16 & 0,94 & 0,16 \\
\hline $\mathrm{C}$ & $\begin{array}{l}\text { Schweizer } \\
\text { Metallbau, } \\
\text { İsviçre }\end{array}$ & $\begin{array}{l}\text { Thermafin } \\
\text { Solar, } \\
\text { ABD }\end{array}$ & Thermafin & $\begin{array}{l}\text { Siyah } \\
\text { krom }\end{array}$ & Bakır & 386 & 0,94 & 0,16 \\
\hline $\mathrm{D}$ & $\begin{array}{l}\text { Tekno Term } \\
\text { AB, İsveç }\end{array}$ & $\begin{array}{l}\text { Granges, } \\
\text { İsveç }\end{array}$ & Sunstrip & $\begin{array}{l}\text { Nikel } \\
\text { pigment, } \\
\text { Anodize } \\
\text { AL }\end{array}$ & Alüminyum & 204 & 0,93 & 0,16 \\
\hline $\mathrm{E}$ & $\begin{array}{l}\text { VDM } \\
\text { Aluminium } \\
\text { Gbmh, } \\
\text { Almanya }\end{array}$ & $\begin{array}{l}\text { VDM } \\
\text { Aluminium } \\
\text { Gbmh, } \\
\text { Almanya }\end{array}$ & Evidal & $\begin{array}{l}\text { Nikel } \\
\text { pigment, } \\
\text { Anodize } \\
\text { Al }\end{array}$ & Alüminyum & 204 & 0,92 & 0,18 \\
\hline $\mathrm{F}$ & $\begin{array}{l}\text { Arbonia, } \\
\text { İsviçre }\end{array}$ & $\begin{array}{l}\text { INCO } \\
\text { Selective } \\
\text { Surface } \\
\text { Ltd } \\
\text { İngiltere }\end{array}$ & Maxorb & $\begin{array}{l}\text { Nikel Folyo } \\
\text { üstü Ni }\end{array}$ & Alüminyum & 204 & 0,94 & 0,09 \\
\hline G & $\begin{array}{l}\text { AMCR, } \\
\text { İsrail }\end{array}$ & $\begin{array}{l}\text { Solarion, } \\
\text { İsrail }\end{array}$ & $\begin{array}{c}\text { Solarion, } \\
2000\end{array}$ & $\begin{array}{l}\text { Siyah } \\
\text { krom }\end{array}$ & $\begin{array}{c}\text { Galvanizli } \\
\text { sac }\end{array}$ & 16 & 0,95 & 0,10 \\
\hline
\end{tabular}


Tablo 3. Hesaplamalarda kullanılan izolasyon malzemeleri ve usl iletim katsayıları

(Sakall, 2005, Özel ve Şengür, 2012; Bektaş vd., 2017)

\begin{tabular}{|c|l|l|}
\hline Simge & Yalıtım Malzemesi & $\begin{array}{l}\text { Isı İletim Katsayısı } \\
\text { (W/m.K) }\end{array}$ \\
\hline I & Poliüretan Köpük & 0,023 \\
\hline II & Plystrene Köpük & 0,029 \\
\hline II & Cam Yünü & 0,032 \\
\hline IV & Taş Yünü & 0,039 \\
\hline V & Cam Köpüğü & 0,052 \\
\hline
\end{tabular}

Farklı özelliklere sahip kollektörlerden elde edilecek 1sı enerjisinin hesaplanmasında aşağıdaki eşitlikler kullanılmıştır. Hesaplamalarda, öncelikle kollektörün kurulacağı koordinat için yeryüzüne gelen günlük toplam 1şınım belirlenmiş ve bu 1şınım 06:00-20:00 zaman periyodunda her saat aralığ hesaplanmıştır. Saatlik güneş 1şınımı hesaplamaları tamamlandıktan sonra, kollektör kayıp ve faydalı enerji hesaplamaları gerçekleştirilmiştir. Saatlik gerçekleştirilen bu hesaplamalar sonucunda, bir yıl içerisinde sıfirın üzerinde hesaplanan tüm değerler toplanarak kollektörden bir yıl için elde edilebilecek faydalı enerji toplamına ulaşılmıştır.

Kollektör yüzeyine gelen ışınım hesabında kullanılan eşitlikler:

(Duffie ve Beckman, 2013; Liu ve Jordan, 1960; Klein, 1977; Munroe, 1980; Lunde, 1980)

$\delta=23.45 \operatorname{Sin}\left(360 \frac{n+284}{365}\right)$

$w_{s}=\cos ^{-1}(-\operatorname{tg} \lambda \cdot \operatorname{tg} \delta)$

$f=1+0.033\left(\operatorname{Cos} \frac{360 n}{365}\right)$

\section{Kollektör ısıl kayıplarını hesaplamada kullanılan eşitlikler:}

$R=\frac{\operatorname{Cos}(\lambda-\varsigma) \operatorname{Cos} \delta \operatorname{Cosh}+\operatorname{Sin}(\lambda-\varsigma) \operatorname{Sin} \delta}{\operatorname{Cos} \lambda \operatorname{Cos} \delta \operatorname{Cosh}+\operatorname{Sin} \lambda \operatorname{Sin} \delta}$

$I_{t}=I_{d o \check{g}} R+I_{d} \frac{(1+\operatorname{Cos} \varsigma)}{2}+\left(I_{d o \check{g}}+I_{d}\right) \frac{(1-\operatorname{Cos} \varsigma) \rho}{2}$

(Tirıs vd., 1997; Klein, 1973; Deris, 1979)

$$
U_{t}=\left\{\frac{N}{\frac{344}{T_{p}}\left[\frac{\left(T_{p}-T_{a}\right)}{\left(N+f_{a}\right)}\right]^{0.31}}+\frac{1}{h_{w}}\right\}^{-1}+\frac{\sigma\left(T_{p}+T_{a}\right)\left(T_{p}^{2}+T_{a}^{2}\right.}{\left[\varepsilon_{p}+0.0425 N(1-\varepsilon\right.}
$$

$H_{o}=\frac{243600 \quad G_{g c}}{\pi} f\left[\operatorname{Cos} \lambda \operatorname{Cos} \delta \quad \operatorname{Sin} \omega_{s}+\frac{\pi}{180}\right.$

$\frac{H_{d}}{H}=1.390-4.027 \frac{H}{H_{o}}+5.531\left(\frac{H}{H_{o}}\right)^{2}-3.108\left(\frac{H}{H_{o}}\right)^{3}=\frac{k}{L}$ 
$U_{e}=\frac{k_{g} c h}{L_{y} A_{c} 1.8236}$

$U_{l}=U_{t}+U_{b}+U_{e}$

Optik kayıpları hesaplamada kullanılan eşitlikler:

(Gordon, 2001;Tirıs vd., 1997)

$\operatorname{Cos} \theta_{T}=\operatorname{Sin} \delta \operatorname{Sin} \lambda \operatorname{Cos} \varsigma-\operatorname{Sin} \delta \operatorname{Cos} \lambda \operatorname{Sin} \varsigma$

$+\operatorname{Cos} \delta \operatorname{Cos} \lambda \operatorname{Cos} \varsigma \operatorname{Cosh}+\operatorname{Cos} \delta \operatorname{Sin} \lambda \operatorname{Sin} \varsigma \operatorname{Cosh}$

$\tau$ değeri üst örtünün geçiş katsayısını ifade etmektedir. Ancak çalışma kapsamında hesaplamalar saatlik yapıldığından, $\tau$ değeri geliş açısına göre hesaplanmıştır. $\tau$ değerinin geliş açısına göre değişimi modellenerek, modelleme sonucunda elde edilen değer kullanılmıştır. $\alpha$ değeri için kullanılan düzeltme katsayısı olan D için de bir model oluşturularak, geliş açısına göre belirlenen D katsayısı kullanılmıştır.

$\alpha=D^{*} \alpha_{n}$

$(\tau \alpha)=\frac{\tau \alpha}{1-(1-\alpha) \rho_{d}}$

Kollektörden elde edlecek faydall isl enerjiyi hesaplamada kullanılan eşitlikler:

(Hsieh, 1986; Duffie ve Beckman, 2013; Gordon, 2001; Tırıs, vd., 1997)

$$
F=\frac{\operatorname{tgh} m(W-D) / 2}{m(W-D) / 2}
$$$$
m=\left(\frac{U_{L}}{k_{p} \delta_{p}}\right)^{1 / 2}
$$

$$
F^{l}=\frac{1 / u_{L}}{W\left\{\frac{1}{U_{L}[D+(W-D) F]}+\frac{1}{c_{b}}+\frac{1}{\pi D h_{f, i}}\right\}}
$$

$$
\begin{aligned}
& V=\frac{m}{\rho\left(\frac{\pi}{4} D^{2}\right)} \\
& R_{e}=\frac{V D}{v}
\end{aligned}
$$

$$
P_{r}=\frac{c_{p} v}{k_{a}}=\frac{v}{\alpha}
$$

$$
R_{e} \leq 2300 \Rightarrow N_{u}=1.86\left(R_{e} P_{r}\right)^{1 / 3}(D / L)^{1 / 3}
$$

$$
R_{e} \geq 2300 \Rightarrow N u=0.027 R_{e}^{0.8} P_{r}^{1 / 3}
$$

$h_{f, i}=\frac{N_{u} k_{a}}{D}$

$F_{R}=\frac{G c_{p}}{U_{L}}\left[1-\exp { }^{-\left(U_{L} F^{l} / G c_{p}\right)}\right]$

$$
\vartheta_{u}=A_{c} F_{r}\left[I_{T}(\tau \alpha)-U_{L}\left(T_{i}-T_{a}\right)\right]
$$

\section{Araştırma Sonuçları ve Tartışma}

Çalışma kapsamında öncelikle Isparta koşullarında güneş kollektörlerinin optimum eğim açısının belirlenmesi için hesaplamalar yapılmıştır. Hesaplamalarda kollektör yüzeyine yıllık toplam gelen güneş 1şınımı miktarları hesaplanmıştır. Hesaplamalar 1-90 derecelik eğimlerde her bir eğim açısı için tekrarlanarak, kollektör yüzeyine gelen enerji miktarları belirlenmiştir. Yaz aylarında düşük eğim açılarında yüksek miktarda enerji sağlanırken, kış aylarında eğim açısındaki artışın belirli bir seviyeye kadar enerji miktarını arttırdığ 1 tespit edilmiştir. Şekil 2'de kesikli çizgi ile gösterilen ve grafiğgin sağ tarafindaki eksenle referanslanan çizgi, hesaplama yapılan eğim açısında $1 \mathrm{~m}^{2}$ alana gelen yıllık toplam enerji miktarlarını göstermektedir. Bu bağlamda yıllık değerler incelendiğinde en yüksek enerji miktarının Isparta için $28^{\circ}$ eğim açısında 1457,83 $\mathrm{kWh} / \mathrm{m}^{2}$ y1l olarak gerçekleştiği tespit edilmiştir. Bu sonuç doğrultusunda kollektör hesaplamaları Isparta koşulları için $28^{\circ}$ eğim açısında gerçekleştirilmiştir. 


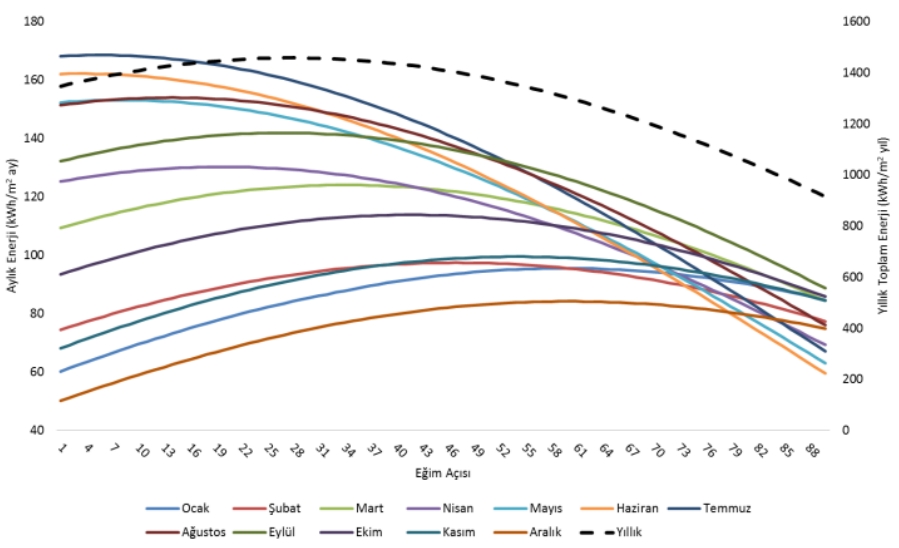

Şekil 2. Isparta koşullarında farklı eğim açılarında $1 \mathrm{~m}^{2}$ alana gelen güneş enerjisi miktarları

Şekil 3'de Isparta koşullarında 7 farklı yutucu yüzeye sahip ve 5 farklı yalıtım malzemesi kullanılan kollektörlerden elde edilecek enerji miktarları gösterilmiştir. Hesaplamalarda en düşük enerji üretimi, AV (A Yutucu Yüzey, V yalıtım malzemesi) için $812,932 \mathrm{kWh} / \mathrm{y} 1 \mathrm{l}$ olarak hesaplanırken, en yüksek değer CI için $1174,305 \mathrm{kWh} / \mathrm{y} 1 \mathrm{l}$ seviyesinde hesaplanmıştır. C ve F yutucu yüzeylerinin enerji değerlerinin oldukça yakın olduğu görülmüştür.

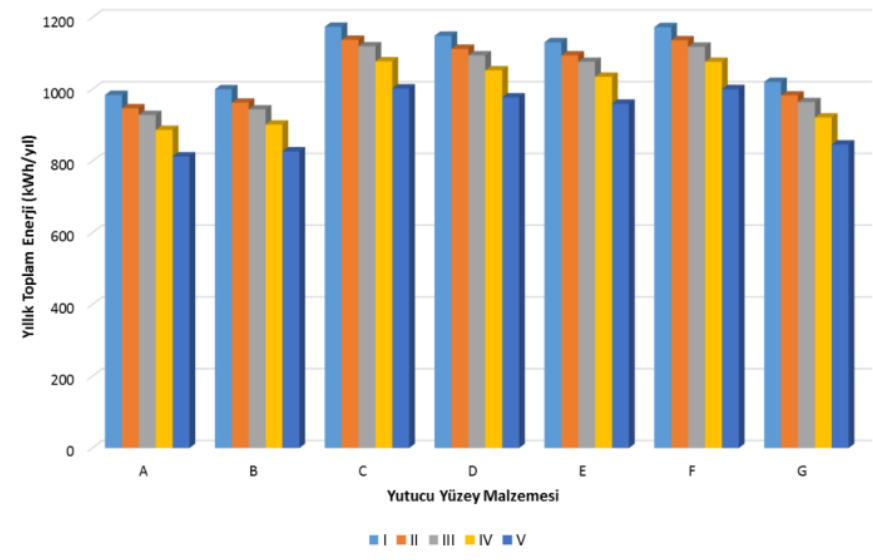

Şekil 3. Isparta koşullarında farklı yutucu yüzey ve yalıtım malzemesi kullanımı sonucunda kollektörlerden alınacak yıllık toplam isıl enerji miktarları

Şekil 4'de Isparta koşullarında kollektörlerde farklı yutucu yüzey ve yalıtım malzemeleri kullanımı sonucunda hesaplanan yıllık verim değerleri gösterilmiştir. Yıllık verim değerleri, enerji değerlerine paralel olarak, en düşük AV uygulaması için \%30 olarak hesaplanırken, yüksek CI uygulaması için \%44 olarak hesaplanmıştır.

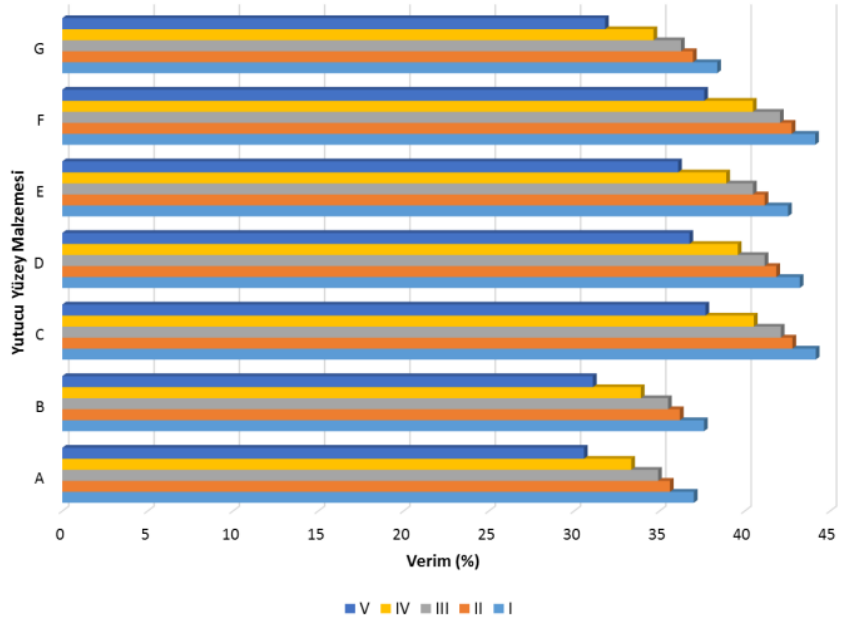

Şekil 4. Farklı yalıtım malzemesi ve yutucu yüzeyler için hesaplanan yıllık verim değerleri

Şekil 5'de farklı boru sayısı ve yalıtım malzemesi kalınlığı kullanılması durumunda Isparta koşullarında güneş kollektöründen elde edilebilecek enerji miktarları gösterilmiştir. $\mathrm{Bu}$ hesaplamalar, yutucu yüzey ve yalıtım malzemesinde CI uygulaması kullanıldığı kabul edilerek gerçekleştirilmiştir. Hesaplamalarda yalıtım malzemesinin kalınlaşmasıyla, 1sıl kayıpların azalması sonucunda, kollektörden elde edilecek enerji miktarlarının arttığı görülmüştür. Benzer şekilde boru sayısının artması, toplam 1sı transfer yüzey alanını arttırarak, elde edilecek enerji miktarlarını yükseltmiştir. Kollektör tasarımlarında $28^{\circ}$ eğim açısında en düşük enerji kazancı $50 \mathrm{~mm}$ yalıtım malzemesi kalınlığında, 6 boru kullanılması durumunda 1151,931 kWh/yıl olarak hesaplanırken en yüksek enerji kazanc1 $125 \mathrm{~mm}$ yalıtım malzemesi kalınlığında 12 boru kullanımında 1262,646 kWh/yıl seviyesinde hesaplanmıştır.

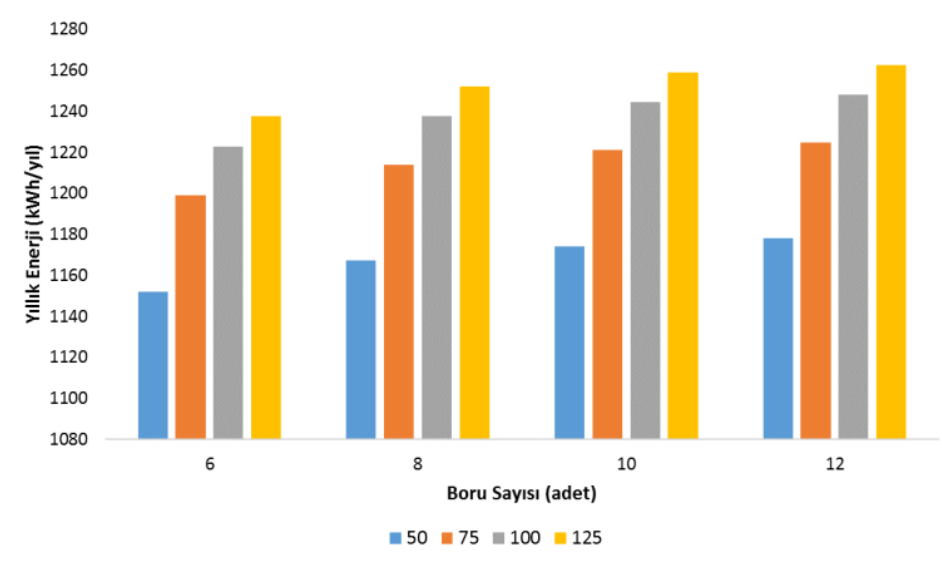

Şekil 5. Farklı boru sayısı ve yalıtım malzemesi kalınlığında kollektörlerden alınacak yıllık toplam ısıl enerji miktarları

Şekil 6'da farklı boru sayısı ve yalıtım malzemesi kalınlığında kollektör verimlerinde meydana gelen değişimler gösterilmiştir. Kollektör verimleri, kazanılan enerji miktarlarına paralel bir değişim göstermiştir. En düşük kollektör verimi $50 \mathrm{~mm}$ yalıtım malzemesi kalınlığında ve 6 boru kullanılması durumunda $\% 43$ olarak hesaplanırken, en yüksek kollektör verimi $125 \mathrm{~mm}$ yalıtım malzemesi kalınlığında 12 boru kullanımında \%47 seviyesinde belirlenmiştir. 
Şekil 6. Farklı boru sayısı ve yalıtım malzemesi kalınlığında hesaplanan kollektör verimleri.

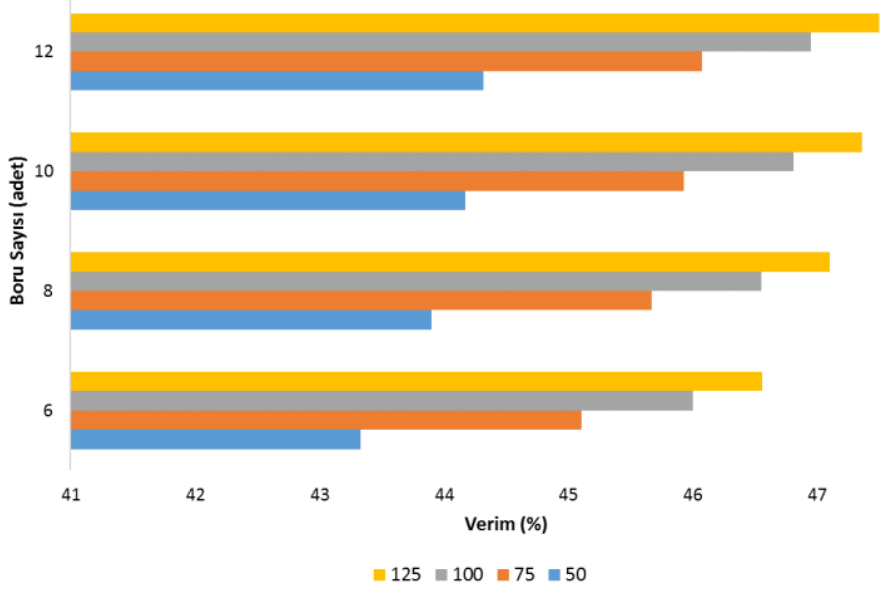

\section{Sonuç}

Çalışma kapsamında; Isparta koşullarında su 1sıtmalı güneş kollektörlerinde kullanılan yutucu yüzey, yalıtım malzemesi, yalıtım malzemesi kalınlığı ve boru sayılarının verim ve kazanılacak enerji kazancı üzerindeki etkilerinin kuramsal olarak belirlenmesi hedeflenmiştir. Hesaplamalarda, 7 farklı yutucu yüzey, 5 farklı yalıtım malzemesi, 4 farklı yalıtım malzemesi kalınlığ ve 4 farklı boru sayısı kullanılmıştır. Hesaplamalarda en düşük kollektör verimi $\% 30$, en yüksek verim $\% 47$ olarak belirlenmiştir. $\mathrm{Bu}$ verim değerleri anlık veya aylık değil, yıllık düzeyde hesaplanmıştır. Hesaplanan verim değerleri literatürde belirlenen \%35-56 aralığındaki değerlerle uyumludur. Literatürde yutucu yüzey malzemesinin verimi \% 7-11 oranında değiştirdiği belirlenirken, çalışma kapsamında yutucu yüzey kaplaması, yutucu yüzey malzemesi ve yalıtım uygulaması kombinasyonunda yapılacak değişikliklerin verimi \% 14'e kadar arttırabildiği belirlenmiştir. Hesaplamalarda seçici yüzey kaplamalarının ve malzeme özelliklerinin çok etkin olduğu görülmüştür. Yutucu yüzey olarak "Thermafin" ve "Maxorb" ticari isimlerine sahip seçici yüzey kullanımının kollektör verimini yükselttiği tespit edilmiştir. Yalıtım malzemesi olarak "Poliüretan Köpük" kullanımının diğer yalıtım malzemelerine göre daha iyi izolasyon sağladığı ve kollektör verimliliğini arttırdığı görülmüștür. Kollektör tasarımında yalıtım malzemesi kalınlığının $50 \mathrm{~mm}$ 'den $75 \mathrm{~mm}$ 'ye çıkartılmasının verimliliği yüksek seviyede etkilediği hesaplanmıştır. Yalıtım malzemesi 75 mm'nin üzerine çıktığında sağlanan verim artış hızının biraz azaldığı görülmüştür. Bu kapsamda $75 \mathrm{~mm}$ 'nin üzerinde yalıtım malzemesi kullanımın kollektör maliyetini arttıracağı göz önünde bulundurulmalıdır. Kollektörde kullanılacak boru sayısının artı̧̧ına paralel olarak verim artı̧̧ sağlanabilmektedir. Bu bağlamda 12 boru kullanılması en yüksek verimi sağlamaktadır.

Çalışma kapsamında elde edilen veriler ile Isparta koşullarında kullanılan su isıtma kollektörlerinde tasarımsal değişiklikler yapılması durumunda verimin toplam $\% 17$ oranında arttırılabileceği sonucuna varılmıştır. Ancak bu çalışma kuramsal bir perpektif sunmaktadır. Çalışmanın deneysel verilerle desteklenmesi daha net bir görüntü ortaya koyacaktır. Ayrıca çalışma kapsamında verimi arttıran parametreler seçilirken, pratikte maliyetinde artacağı göz önünde bulundurulmalıdır.

\section{Simgeler}

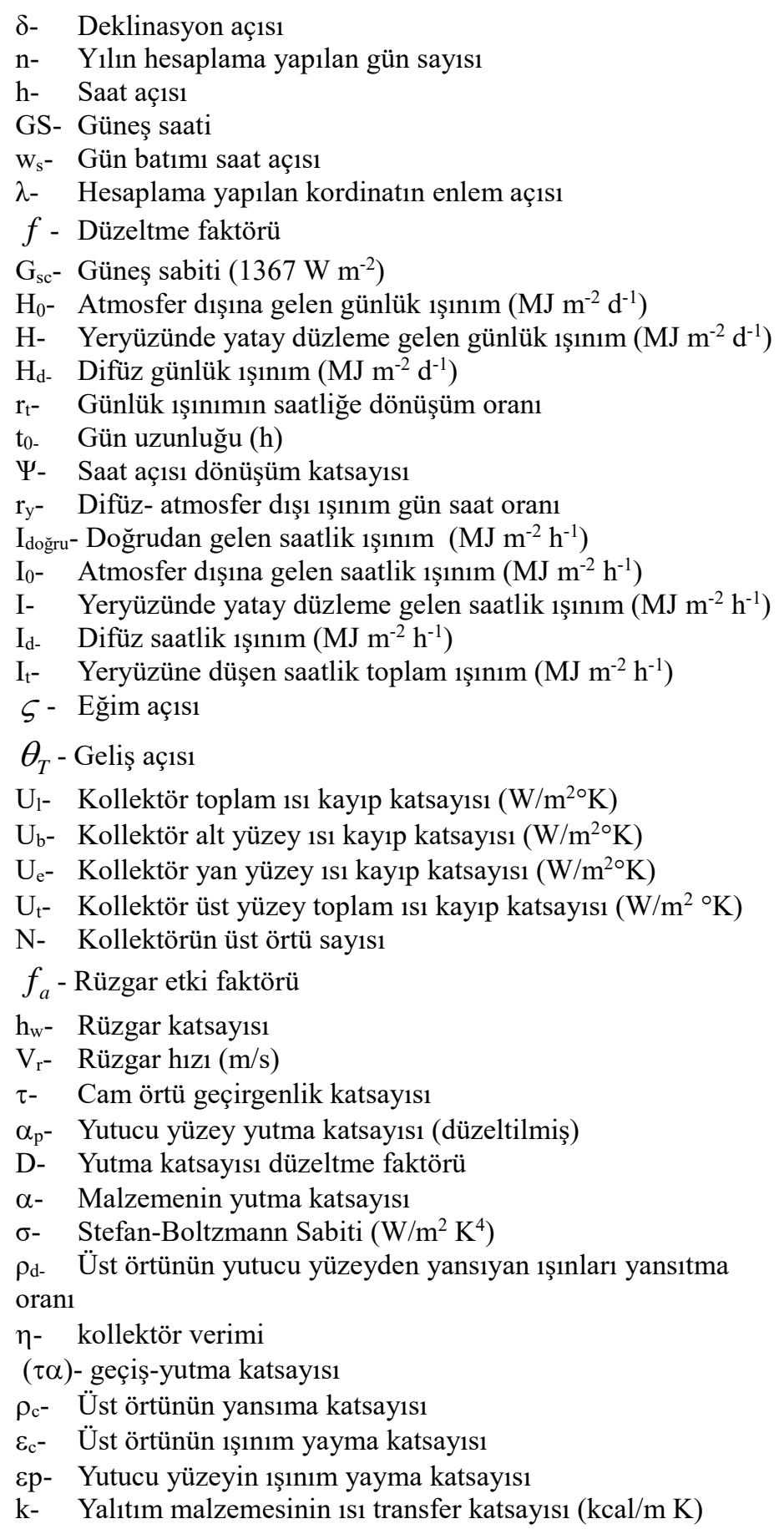

$\delta$ - Deklinasyon açısı

n- Yılın hesaplama yapılan gün sayısı

h- Saat açısı

GS- Güneş saati

- Gün batımı saat açıs

$\lambda$ - Hesaplama yapılan kordinatın enlem açıs

$f$ - Düzeltme faktörü

$\mathrm{G}_{\mathrm{sc}^{-}}$Güneş sabiti (1367 $\left.\mathrm{W} \mathrm{m}^{-2}\right)$

$\mathrm{H}$ - Yeryüzünde yatay düzleme gelen günlük ışııım $\left(\mathrm{MJ} \mathrm{m}^{-2} \mathrm{~d}^{-1}\right)$

$\mathrm{H}_{\mathrm{d}-} \quad$ Difüz günlük ışınım $\left(\mathrm{MJ} \mathrm{m}^{-2} \mathrm{~d}^{-1}\right)$

$\mathrm{r}_{\mathrm{t}^{-}} \quad$ Günlük ışınımın saatliğe dönüşüm oranı

$\mathrm{t}_{0-} \quad$ Gün uzunluğu $(\mathrm{h})$

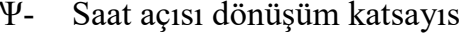

$r_{y^{-}} \quad$ Difüz- atmosfer dış1 1şınım gün saat oran

$\mathrm{I}_{0^{-}} \quad$ Atmosfer dışına gelen saatlik ışınım $\left(\mathrm{MJ} \mathrm{m}^{-2} \mathrm{~h}^{-1}\right)$

I- Yeryüzünde yatay düzleme gelen saatlik ışınım $\left(\mathrm{MJ} \mathrm{m}^{-2} \mathrm{~h}^{-1}\right)$

$\mathrm{I}_{\mathrm{d}-} \quad$ Difüz saatlik 1 şınım $\left(\mathrm{MJ} \mathrm{m}^{-2} \mathrm{~h}^{-1}\right)$

$\mathrm{I}_{\mathrm{t}^{-}} \quad$ Yeryüzüne düşen saatlik toplam 1 şınım $\left(\mathrm{MJ} \mathrm{m}^{-2} \mathrm{~h}^{-1}\right)$

$\varsigma$ - Eğim açısı

$\theta_{T}$ - Geliş açısı

$U_{b^{-}}$Kollektör alt yüzey 1sı kayıp katsayısı $\left(\mathrm{W} / \mathrm{m}^{2 \circ} \mathrm{K}\right)$

$\mathrm{U}_{\mathrm{e}}-$ Kollektör yan yüzey $1 \mathrm{~s} 1$ kayıp katsayısı $\left(\mathrm{W} / \mathrm{m}^{2 \circ} \mathrm{K}\right)$

$\mathrm{U}_{\mathrm{t}}-$ Kollektör üst yüzey toplam $1 \mathrm{~s} 1$ kayıp katsayısı $\left(\mathrm{W} / \mathrm{m}^{2}{ }^{\circ} \mathrm{K}\right)$

sayis

$\mathrm{h}_{\mathrm{w}}-$ Rüzgar katsayıs

$\mathrm{V}_{\mathrm{r}^{-}}$Rüzgar hızı $(\mathrm{m} / \mathrm{s})$

$\tau$ - $\quad$ Cam örtü geçirgenlik katsayısı

$\alpha_{p^{-}} \quad$ Yutucu yüzey yutma katsayısı (düzeltilmiş)

D- Yutma katsayısı düzeltme faktörü

$\alpha-\quad$ Malzemenin yutma katsayis

$\sigma-\quad$ Stefan-Boltzmann Sabiti $\left(\mathrm{W} / \mathrm{m}^{2} \mathrm{~K}^{4}\right)$

$\rho_{\text {d- }} \quad$ Üst örtünün yutucu yüzeyden yansıyan ışınları yansıtma oran1

$\eta$ - kollektör verimi

$(\tau \alpha)$ - geçiş-yutma katsayısı

$\rho_{c^{-}} \quad$ Üst örtünün yansıma katsayıs

$\varepsilon_{c^{-}} \quad$ Ust örtünün 1şınım yayma katsayısı

k- Yalıtım malzemesinin 1sı transfer katsayıs $(\mathrm{kcal} / \mathrm{m} \mathrm{K})$ 
c- Kollektör çevresi (m)

L- Yalıtım malzemesi kalınlığı (m)

h- Kollektörün yan kenar yüksekliği (m)

$\mathrm{A}_{\mathrm{c}^{-}}$Kollektör alanı $\left(\mathrm{m}^{2}\right)$

$\mathrm{L}_{\mathrm{e}}-$ Yan yüzey yalıtım malzemesi kalınlığı (m)

F- Kollektör kanat verimi katsayısı

F'- Kollektör etki faktörü

W- Boru eksenleri arasındaki mesafe (m)

D- Boru iç çapı (m)

$\mathrm{k}_{\mathrm{p}}-$ Yutucu plakanın 1sıl iletkenlik katsayısı ( $\left.\mathrm{kcal} / \mathrm{m} \mathrm{h} \mathrm{K}\right)$

$\delta_{\mathrm{p}^{-}} \quad$ Yutucu plakanın kalınlığı $(\mathrm{m})$

$\mathrm{C}_{\mathrm{b}^{-}}$Kaynak malzemesinin $1 \mathrm{~s} 1$ geçiş direnci $(\mathrm{kcal} / \mathrm{m} \mathrm{h} \mathrm{K})$

$\mathrm{h}_{\mathrm{fi}}{ }^{-}$Boru iç yüzeyi ile sıvı arasındaki ısı geçiş katsayısı

(kcal/m $/ \mathrm{m}^{2} \mathrm{~K}$ )

$\mathrm{F}_{\mathrm{R}}-$ Kollektör kanat verimi

G- Kollektör birim alanına düşen kütlesel debisi $\left(\mathrm{kg} / \mathrm{h} \mathrm{m}^{2}\right)$

$\mathrm{c}_{\mathrm{p}^{-}} \quad$ Suyun özgül 1sısı ( $\left.\mathrm{kcal} / \mathrm{kg} \mathrm{C}\right)$

$\mathrm{Q}_{\mathrm{u}^{-}}$Kolektörden kazanılan enerji $\left(\mathrm{W} / \mathrm{m}^{2}\right)$

Ta- Çevre sıcaklığı $\left({ }^{\circ} \mathrm{K}\right)$

Ti- Akışkanın kolektöre giriş sıcaklığ $\left({ }^{\circ} \mathrm{K}\right)$

Tp- Yutucu plaka sicaklığ $\left({ }^{\circ} \mathrm{K}\right)$

$v$ - Kinematik vizkosite $\left(\mathrm{m}^{2} / \mathrm{s}\right)$

$\mathrm{V}$ - Akışkan hızı (m/s)

$\mathrm{R}_{\mathrm{e}}-$ Reynolds sayıs1

$\mathrm{k}_{\mathrm{a}^{-}} \quad$ Akışkanın 1sıl iletkenli katsayısı ( $\left.\mathrm{kcal} / \mathrm{m} \mathrm{h} \mathrm{K}\right)$

$\mathrm{P}_{\mathrm{r}^{-}}$Prandtl sayısı

$\mathrm{N}_{\mathrm{u}^{-}}$Nusselt say1s1

\section{Kaynakça}

Bektaş, V. (2017). Binalarda Isı Yalıtımının Önemi ve Isı Yalıtım Malzemesi Kalınlığının Yalıtıma Etkisi. Bilecik Şeyh Edebali Üniversitesi Fen Bilimleri Dergisi, 4 (1), 36-42.

Deris, N. (1979). Solar energy, solar water heating technique. Sermet Matbaas1, Istanbul.

Duffie J. and Beckman W. (2013). Solar Engineering of Thermal Processes, 4th ed., 163: 236-319, New Jersey

Gordon, J. (2001). Solar energy: the state of the art. ISES, New York.

Günder. (2002). Güneş ülkemizin enerji geleceğidir. Erişim Tarihi: 15/08/2020, erişim adresi: https://gunder.org.tr/wpcontent/uploads/gunder-enerjimaden.pdf.

Hsieh, J.S.(1986). Solar energy engineering. Prentice Hall Inc., New York.

Kılıçkap, S., Yıldız, C., Çakmak, G. (2015). Elazı̆̆ iklim koşullarında sıcak sulu güneş kolektörlerine ilişkin verimlerin araştırılması. Dicle Üniversitesi Mühendislik Dergisi, 6(2), 103-110.

Klein, S.A. (1973). The effects of thermal capacitance upon the performance of flat plate collectors. M.Sc. Thesis, University of Wisconsin.

Klein, S.A. (1977). Calculation of monthly average insolation on tilted surfaces. Solar Energy 19, 325-329.

Korkmaz, M. (2006). Düzlemsel Güneş Kollektörlerinde Farklı Profillerdeki Emici Plakaların Deneysel İncelenmesi. Gazi Üniversitesi Fen Bilimleri Enstitüsü Makine Öğretimi ABD Yüksek Lisans Tezi.

Kumar, R., Rosen, M.A. (2010). Thermal performance of integrated collector storage solar water heater with corrugated absorber surface. Applied Thermal Engineering, 30, 17641768 .
Liu, B.Y.H.; Jordan, R.C. (1960). The interrelationship and characteristics and distribution of direct, diffuse and total solar radiation. Solar Energy 4, 1-10.

Lunde, P.J. (1980). Solar thermal engineering: space heating and hot water systems. John Wiley and Sons: New York.

Madhukeshwara, N., Prakash, E.S. (2012). An investigation on the performance characteristics of solar flat plate collector with different selective surface coatings. Internatıonal Journal of Energy And Envıronment 3(1), 99-108.

Munroe, M.M. (1980). Estimation of totals of irradiance on a horizontal surface from UK: average meteorological data. Solar Energy 24, 235-238.

Özel, M., Şengür, S. (2012). Farklı Yakıt Türü ve Yalıtım Malzemelerine Göre Optimum Yalıtım Kalınlığının Belirlenmesi. Tesisat Mühendisliği Sayı 132, 5-11.

Sakallı, U. (2005). Antifirizli Sulu Vakumlu Isı Borulu Güneş Kollektörü İle Klasik Direkt Dolaşımlı Güneş Kollektörlerinin Verimlerinin Karşılaştırılması. Zonguldak Karaelmas Üniversitesi Fen Bilimleri Enstitüsü Makine Eğitimi Anabilim Dalı Bilim Uzmanlığı Tezi.

Shariaha, A.M., Rousana A., Rousanb Kh.K., Ahmada A.A.(1999). Effect of thermal conductivity of absorber plate on the performance of a solar water heater. Applied Thermal Engineering 19, 733-741.

Tırıs, M.; Tırıs, C.; Erdallı (1997). Güneş Enerjili Su Isıtma Sistemleri, Tübitak M.A.M. Matbaası, Kocaeli, 1-60. 